\title{
GEOGRAFIZANDO O FUTEBOL: DO GLOBAL AO LOCAL
}

\section{C. CAMPOS 1}

Instituto Federal de Educação, Ciência e Tecnologia do Rio Grande do Norte Israelcayo2007@hotmail.com - cayo.cayo2010@hotmail.com

Artigo submetido em março/2013 e aceito em junho/2013

\section{RESUMO}

No Brasil, em razão da relevância do futebol, encontram-se territórios que possuem sua gestão voltada para esse esporte. Entretanto, pouco se tem estudado como esses territórios vêm se organizando no espaço, avaliando sua evolução e dinâmica desde suas origens na Inglaterra urbana-industrial se difundindo pelos demais continentes. O trabalho se constitui em um estudo exploratório, apresentando uma reflexão de como o futebol se organizou, de um esporte das altas classes inglesas se tornando um esporte popular, presente em grande parte do mundo ocidental. O recorte histórico abrange informações sobre um olhar geográfico no qual mostra-se a expansão do futebol, bem como os organismos que tornaram possível essa expansão.

PALAVRAS-CHAVE: Futebol, Território, FIFA, Natal-RN.

\section{GEOGRAPHY OF FOOTBALL: THE GLOBAL TO LOCAL}

\section{ABSTRACT}

In Brazil, due to the importance of football, are territories that have their management facing the sport. However, little has been studied how these territories have been organizing themselves in space, and evaluating their dynamic evolution from its origins in England urban-industrial spreading by other continents. The work constitutes an exploratory study, showing a reflection of how football is organized, a sport of the English upper classes becoming a popular sport, present in much of the Western world. The historical covers information about a geographic look at which shows the expansion of football, as well as the organizations that made this expansion possible.

KEYWORDS: football, territory, FIFA, Natal-RN. 


\section{GEOGRAFIZANDO O FUTEBOL: DO GLOBAL AO LOCAL}

\section{INTRODUÇÃO}

O futebol, nas diversas sociedades e em diferentes tempos históricos, tem cumprido um papel mais complexo do que o simples ato de 11 jogadores de cada time, estarem chutando uma bola para dentro de uma baliza ou trave (ou gol, de maneira popular). Diante dessa complexidade, a ordem espacial do futebol se evidencia como um motor de mobilização e organização territorial, tornando-se, portanto, em um tema genuinamente geográfico, mas que tem sido pouco estudado pela ciência geográfica.

O futebol é um esporte de origem britânica que, inicialmente era praticado somente por pessoas privilegiadas social e economicamente, mas se tornou o esporte mais popular do mundo, sendo capaz de organizar ou reorganizar territórios em múltiplas escalas geográficas. A sua difusão tem um caráter de apropriação espacial, ou seja, de territorialidade desenvolvida por este fenômeno desportivo. O futebol possui e coloca em prática estratégias de controle social e de difusão territorial, com isso se firmando como uma prática social, politica, econômica e cultural; que resulta na apropriação de territórios, administrados por agentes envolvidos com essa prática desportiva (BRUNI, 1994).

Nessa perspectiva, o futebol contemporâneo não pode ser analisado somente como um tipo de esporte, mas como um fenômeno que deixa antever o universo de significados simbólicos, psíquicos, sociais, culturais, históricos e espaciais inesgotáveis que envolvem multidões concentradas em torno de um espetáculo que empolga e emociona sociedades, nações, países, estados e cidades e tem conquistado a adesão cada vez maior de pessoas de diferentes camadas sociais (BRUNI, 1994).

O futebol é o esporte mais praticado no mundo, segundo dados da Federação Internacional de Futebol Associado (FIFA), em seu último censo realizado no ano de 2007; Existem mais de 265 milhões de jogadores ativos desse esporte em todo mundo (FEDERAÇÃO INTERNACIONAL DE FUTEBOL ASSOCIADO, 2011). Se levarmos em consideração a prática desse esporte em áreas mais longínquas e não cadastradas por essa organização, os números podem ser ainda mais elevados.

Considerando-se a quantidade de audiência obtida na última Copa do Mundo ${ }^{1}$, realizada em 2010 na África do Sul, o total de pessoas que assistiram a competição foi de 3,2 bilhões de espectadores, o que a época correspondia a aproximadamente $46 \%$ da população mundial, superando a Copa do Mundo anterior disputada na Alemanha em 2006. Na Copa do Mundo de 2010, a partida final disputada entre as seleções da Espanha e Holanda foi a maior audiência do torneio com mais de 619 milhões de telespectadores (FEDERAÇÃO INTERNACIONAL DE FUTEBOL ASSOCIADO, 2011).

No Brasil, o futebol surgiu a partir do mês de abril de 1895; por intermédio do britânico Charles Miller. Este trouxe as regras do jogo, ensinando-a a seus companheiros, realizando uma partida de futebol no Brasil em um terreno baldio da alta classe média paulistana (MÁXIMO, 1999).

\footnotetext{
${ }^{1}$ Principal torneio entre seleções disputado no planeta. 
A partir daí o Brasil passa a difundir esse esporte passando a ser conhecido, dentre outras alcunhas, como o "País do Futebol", graças aos títulos mundiais alcançados pela Seleção Brasileira de Futebol $^{2}$, e da nossa quase sempre capacidade de formar uma grande quantidade de bons jogadores a cada ano. Jogadores esses, que são reconhecidos em todo mundo dada a crescente comercialização de desportistas para clubes estrangeiros. No Brasil, cerca de $44 \%$ dos brasileiros com idade acima dos 16 anos acompanham o esporte, seja através da prática do jogo ou do acompanhamento do mesmo através da mídia (DAMATTA, 2010), embora seja muito difícil mensurar em valores estatísticos o sentimento que os brasileiros sentem por esse esporte.

Apesar de ter se iniciado nas classes mais aquinhoadas, o futebol acabou se tornando o esporte das "massas" se difundindo rapidamente pela América Latina, principalmente em países como Argentina, Uruguai e Brasil, acompanhando o processo de industrialização que as principais cidades desses países estavam a se submeter (JESUS, 2002).

Por meio da pesquisa bibliográfica pretendemos analisar as origens do futebol, bem como se deu sua difusão de territórios britânicos para os demais países, passando pelo Brasil e chegando a cidade de Natal, capital do Rio Grande do Norte.

O futebol enquanto, um esporte que acabou se tornando elemento de difusão de uma cultura britânica se instaurou em todo mundo dado à influência do imperialismo inglês, chegando ao Brasil por meio de estudantes - caso de Charles Miller, o introdutor do futebol no Brasil - e proletários ingleses, sendo o modo de difusão do esporte pelo território de forma desconexa e difusa, não havendo interconexão direta entre as cidades brasileiras.

\section{AS ORIGENS DO FUTEBOL}

Nas origens do futebol, existem citações que remetem a jogos que envolvem a disputa pela bola em vários locais do mundo, podemos citar os povos Astecas que praticavam o Tlachtli, um misto de basquete e futebol, onde a bola de borracha era tocada somente com os joelhos ou quadris e deveria ser passada por uma circunferência similar as cestas utilizadas em jogos de basquete, após as partidas, a "equipes" derrotadas eram decapitadas em um ritual honroso e sangrento (FIGUEIREDO, 2002).

Os chineses praticavam o Kemari nos séculos II ou III A.C (SANTOS, 1981). Na Europa medieval, jogos semelhantes ao futebol eram bastante populares, sendo o Calcio, ${ }^{3}$ muito comum em cidades importantes como o caso de Florença. O Calcio viria a ser um dos "ancestrais" mais próximos do futebol moderno, como também de outro esporte moderno, o rúgbi.

O futebol só passou a existir a partir do século XIX. No entanto, devemos reconhecer que esses jogos criados em diferentes regiões do mundo, cada um com suas regras próprias, se popularizaram e acabaram por contribuir para a essência do esporte moderno (LIMA, 2002).

O futebol surgiu enquanto esporte, após a tentativa de se estabelecer regras únicas para o jogo, pois embora já bem popular nas universidades da Inglaterra no século XIX, cada

\footnotetext{
${ }^{2}$ Conquistados nos anos de 1958 na Suécia, 1962 no Chile, 1970 no México, 1994 nos Estados Unidos e 2002 no Japão e Coréia do Sul.

${ }^{3}$ Esse é o nome que até hoje designa o termo futebol na Itália. 
universidade possuía suas próprias regras. A diversidade de regras entre membros praticantes de diferentes universidades inglesas ${ }^{4}$, fez com que existisse a necessidade de uma padronização das regras do jogo. Já que muitas equipes de diferentes universidades se enfrentavam. Dentre as universidades que adotavam o modelo mais parecido com as regras do futebol atual, destaca-se a Universidade de Cambridge que foi essencial para a futura organização das regras do esporte (FEDERAÇÃO INTERNACIONAL DE FUTEBOL ASSOCIADO, 2012).

A formulação das regras do esporte acabou por decidir que no futebol não se poderia utilizar as mãos ${ }^{5}$ e que eram consideradas infrações os chutes nas canelas. Essas seriam as primeiras regras do futebol, em 1848, numa conferência em Cambridge. Em 1861, foi instituída a Football Association, que foi responsável pela produção do primeiro conjunto de regras do esporte, sendo 1863, considerado o ano do nascimento do futebol moderno. Em 1875, foi estabelecida a regra do tempo de 90 minutos e em 1891 foi estabelecido o pênalti, para punir a falta dentro da área. (SUA PESQUISA.COM, 2013).

Somente em 1907 foi estabelecida a regra do impedimento que a principio tornava o jogo irregular ao atacante que estivesse à frente do antepenúltimo jogador de defesa, essa regra foi alterada em 1925, quando o offside seria marcado para o atacante que estivesse à frente apenas do penúltimo jogador de defesa (FEDERAÇÃO INTERNACIONAL DE FUTEBOL ASSOCIADO, 2012).

Discordâncias sobre regras acabaram por causar uma cisão entre os membros fundadores do esporte, o que gerou a existência de dois esportes oriundos dessas reuniões: O futebol e o Rúgbi, que optou por manter a utilização das mãos por todos os seus desportistas. (SUA PESQUISA.COM, 2013).

A partir da Football Association, surge o futebol. Em 1885, foi iniciada a era do profissionalismo do esporte na Inglaterra, no ano seguinte, era criada a Diretoria Internacional de Futebol Associado (IFAB), responsável pela criação das chamadas dezessete regras do jogo, bem como até hoje ainda responsável pela modificação de qualquer regra do esporte (BLATTER, 1998).

A padronização do esporte por meio da criação de regras para prática do desporto abrangeu de inicio os praticantes vindos das classes mais ricas da Inglaterra, grande parte da população oriunda da classe trabalhadora que já se familiarizava na prática desse esporte, ainda desconhecia qualquer padronização de regras, continuando a praticar o jogo de acordo com suas normas, excedendo a virulência o que por muitas vezes acabava por prejudicar as condições físicas dos operários, nesse período de plena revolução industrial na Inglaterra, era um prejuízo para a burguesia ter parte de sua força de trabalho incapaz devido às contusões oriundas dessa prática desportiva (LIMA, 2002).

No entanto, proibir a prática do futebol sem regras era prejudicial, dada a importância que esse esporte possuía de despolitizar a classe operária na década de 1860 (RAMOS, 1984). A solução para tal problema foi à burguesia, recebendo contribuição do estado, padronizar o esporte para as classes operárias. Sobre o desejo da classe burguesa de difundir essa padronização das regras,

\footnotetext{
${ }^{4}$ Cada escola inglesa praticava o jogo de acordo com suas regras, algumas permitiam aos seus atletas utilizaram durante a partida as mãos e os pés, outras escolas só permitiam a utilização dos membros inferiores para a condução da bola (FEDERAÇÃO INTERNACIONAL DE FUTEBOL ASSOCIADO, 2012).

${ }^{5}$ Com exceção da função de goleiro que só seria criada em 1871, que seria o único jogador que poderia colocar as mãos na bola e deveria ficar próximo ao gol para evitar a entrada da bola (SUA PESQUISA.COM, 2012).
} 
Podemos perceber que a regulamentação das regras do Futebol, e outros jogos, veio em um momento histórico onde o operariado começa a reivindicar os seus direitos e começavam a se tornar uma classe política. Nada melhor para a burguesia industrial do que controlar, a partir da criação de regras, um jogo em que a maioria proletária praticava (LIMA, 2002, p. 06).

Graças ao controle da burguesia industrial, o futebol rapidamente se apossou da realidade trabalhadora inglesa, se tornando num objeto de identificação das grandes massas trabalhadoras do país. A grande receptividade das classes trabalhadoras ao futebol e da utilização do esporte pela burguesia, como forma de controlar e alienar os trabalhadores, o futebol se tornou importante para construção do território inglês, sendo um elemento capaz de explicar e de ser explicado pelo desenvolvimento tecnológico e científico existente no fim do século XIX e inicio do século XX (LIMA, 2002).

\subsection{Os primeiros campeonatos entre clubes}

O primeiro torneio de futebol entre clubes ingleses correu por volta dos anos de 1871 e 1872, sendo o mais antigo torneio entre clubes do mundo a Copa de Futebol Associado (F.A Cup) mais conhecida nos países de língua portuguesa como a Copa da Inglaterra. No primeiro ano de sua realização o campeão foi o Wanderes, clube que nem existe mais como profissional. Atualmente, esse torneio que se organiza em jogos únicos onde o vencedor se classifica para a fase seguinte ${ }^{6}$. A F. A Cup, foi uma idealização do secretário honorário da Football Association, Charles Alcock, e em sua primeira edição contou com apenas 15 clubes, atualmente, esta competição é disputada por mais oitocentas equipes (FEDERAÇÃO DE INGLESA DE FUTEBOL, 2013).

A partir da criação da F.A Cup, o futebol passou atrair mais fãs e equipes que passaram a desejar ser o melhor time da Inglaterra, novos clubes foram criados e novos processos de disputas territoriais passaram a existir, cidades grandes como Manchester e Londres passaram a contar com mais de um clube, que disputavam a atenção e geravam conflitos indentitários entre os fãs dessas equipes. O futebol passou a se expandir pelo território inglês o que levaria em seguida a uma expansão em nível mundial.

\subsection{A expansão do futebol pelo mundo}

O futebol, que se tornara um esporte popular na Inglaterra, ainda no século XIX, passou a se espalhar para as demais nações do Reino Unido. Em 30 de novembro de 1872, realizava-se o primeiro confronto internacional de seleções, envolvendo as seleções inglesa e escocesa. Um pouco mais de três mil e quinhentas pessoas viram o jogo acabar em zero a zero, o que em nada

\footnotetext{
${ }^{6}$ Se o jogo terminar empatado, um novo jogo é marcado. 
evitou que as rivalidades históricas entre escoceses e ingleses conseguissem um novo campo de disputa, o futebol (FUTEBOL INGLÊS ONLINE, 2012).

O futebol deixava de ser uma prática escolar e passava ao gosto popular, levando ainda no século XIX a seus estádios, públicos superiores a dez mil torcedores, e atraindo cada vez mais a população de classe média. Nesse período o futebol ainda apresentava um caráter urbano (JESUS, 2002), o que é facilmente explicado pelos primeiros países onde a prática do futebol estava sendo disseminada, o Reino Unido e em especial a Inglaterra foram às primeiras nações onde se desenvolveu o processo de urbanização em massa através da revolução industrial.

Em meados do século XIX metade da população inglesa vivia nas cidades, esse percentual cresceu ao longo dos anos e o futebol como prática desportiva oriunda desse processo de urbanização passou a se espalhar pelo continente europeu. O futebol se difundiu pelo mundo através do imperialismo inglês, sendo bancos, telégrafos, estradas de ferro e transportes urbanos os elementos que tornaram possível a difusão do esporte para outros países (SANTOS, 1981).

Sobre a relação do futebol com o meio urbano e as fábricas criadas a partir da revolução industrial, clubes ainda hoje muito populares na Inglaterra como o Manchester e o Arsenal foram criados por trabalhadores de fábricas, financiados por seus patrões. Podemos analisá-las de acordo com a visão de Jesus:

Os jogadores devem obedecer estritamente às instruções do treinador "ter disciplina tática", sob a pena de perder vaga na equipe, pois trata-se de um empregado empenhado em produzir ao máximo e em respeitar a hierarquia dentro do clube, para manter seu provisório posto de trabalho, por muitos disputados (JESUS, 2002, p.3) .

De acordo com essa visão, o futebol se torna fruto de uma sociedade urbana industrial, e por isso mesmo é adequado em suas regras e tática a uma hierarquia e divisão do trabalho original dos processos de produção urbana. Portanto, a partir do século XIX, quando esse processo de expansão urbano-industrial se expande, partindo da Inglaterra para todos os outros continentes, o futebol acaba por se inserir no contexto mundial. (JESUS, 2002).

O comércio, construção de ferrovias e outras infraestruturas, formaram os meios pelos quais o futebol se espalhou do Reino Unido para os demais países (JESUS, 1998), a partir dessas relações comerciais, o futebol chega às colônias britânicas da África, Ásia e Oceania ${ }^{7}$, como também aos países que mantinham relações comerciais com os ingleses, essa inserção do esporte sempre se dava nas cidades onde o comércio $^{8}$ e a indústria começavam a se estabelecer, cidades como Gênova, Buenos Aires, Montevidéu e Le Havre foram de extrema importância para a implantação desse esporte em seus respectivos países (JESUS, 2002).

O primeiro jogo internacional entre seleções não europeias acontecia em 1886, entre Estados Unidos da América e Canadá - tendo o jogo sido vencido pelos canadenses - no entanto, apesar de os estadunidenses terem sido pioneiros na prática do esporte no mundo, graças ao forte comércio já existente no Atlântico Norte no fim do século XIX, o futebol foi banido das universidades norte - americanas, devido à politicas de nacionalismo, o que deixou o esporte em

\footnotetext{
${ }^{7}$ Sendo a Austrália a primeira nação deste continente a realizar uma partida de futebol no ano de 1880.

${ }^{8}$ Principalmente através das zonas portuárias.
} 
estagnação no país. O futebol só voltaria a ganhar notoriedade nos Estados Unidos graças aos imigrantes italianos que praticavam o esporte inglês e que por isso mesmo eram acusados de antiamericanos pela população local (JESUS, 2000).

Antes do final do século XIX, o futebol estava se popularizando em todo mundo, muitas federações nacionais e clubes de futebol surgiram, dando uma nova espacialidade a suas populações. Clubes que até hoje possuem grandes torcidas e estádios passaram a ganhar notoriedade antes mesmo da virada do século, entre eles se destacam o Liverpool, o Hamburgo e o Futbol Club Barcelona. Este último clube que traz consigo não só a bandeira do esporte, como também a ideia de uma resistência ao nacionalismo espanhol sobre os catalães. Seu slogan, "Barcelona, More Than a Club" demonstra a importância desse clube de futebol enquanto elemento chave de uma identidade territorial diferente da espanhola dentro do país (JESUS, 1999).

Em 1867, o futebol foi mencionado pela primeira vez na América do Sul, em um jornal, 0 Buenos Aires Standard publicou um anuncio, com o estimulo de Edward Mullrall, que era editor do jornal, onde eles chamavam a atenção, para o até então novo esporte, chamado Football Association, que estava fazendo sucesso não só entre os alunos de descendência inglesa, como entre os operários do pais. (GORGAZZI; BROBOWSKY, 1999).

Gradativamente, os técnicos que chegavam à Argentina, para construir o novo sistema ferroviário, traziam para as Américas o novo esporte. No primeiro jogo realizado em 20 de junho de 1867, no Campo de Palermo em Buenos Aires, as equipes eram formadas apenas por oito jogadores cada (GORGAZZI; BROBOWSKY, 1999).

O futebol que surgira na Inglaterra difundiu-se pelo mundo. Diversas associações nacionais surgiram em vários países antes mesmo da chegada do século $X X$, o que contribuiu cada vez mais pra expansão e popularização do futebol, dentre as federações criadas destacamse a dinamarquesa, holandesa, italiana, $\operatorname{argentina}{ }^{10}$, chilena e uruguaia.

\subsection{A FIFA, enquanto organismo difusor do esporte}

Com a expansão do futebol pelo mundo, o controle desse esporte não era estabelecido por uma só uma federação, outras organizações futebolísticas passaram a defender o fim da hegemonia politica do esporte pela Inglaterra. Entre estas organizações, se destaca a Federação Francesa de Futebol (FFF), que foi responsável pela criação da Federação Internacional de Futebol Associado (FIFA), em 21 de maio 1904. Essa organização foi criada com o intuito de realizar um campeonato internacional de seleções e acabar com a supremacia inglesa no esporte. (TRAVINHA ESPORTES, 2010).

Entre os fundadores da FIFA se destacam quatro amigos, o advogado Robert Guérin, o banqueiro holandês C. A. W. Hirschman, o industrial gráfico francês Henry Delaunay e o editor francês Jules Rimet ${ }^{11}$ (TRAVINHA ESPORTES, 2010).

\footnotetext{
9 "Barcelona, mais que um clube".

10 Primeira federação nacional de futebol da América do Sul.

${ }^{11}$ Sendo o primeiro, o primeiro presidente da FIFA, e o último o maior idealizador da criação de um torneio internacional de seleções.
} 
A FIFA contou em sua fundação apenas com países europeus: Bélgica, Dinamarca, Espanha, França, Holanda, Suécia e Suíça. O que denota que apesar da difusão do esporte em todo mundo, este ainda era controlado pela ideologia da superioridade europeia. Somente cinco anos depois, a partir de 1909, a FIFA passava a ter em seus integrantes federações de outros continentes, como a Sul-Africana (1909), argentina e chilena (1911), dos Estados Unidos da América (1913) e a Confederação Brasileira de Futebol (1914) (TRAVINHA ESPORTES, 2010).

Desde sua fundação até 1929, o principal torneio entre seleções era os Jogos Olímpicos, sendo esse apenas disputado por jogadores amadores. O futebol cada vez mais ganhava o amor de seus espectadores e modificava os espaços urbanos da Europa e América do Sul. Prova disso, foi que durante os jogos olímpicos de 1924, disputados em Paris, mais de sessenta mil pessoas assistiram a final vencida pelo Uruguai sobre a Suécia. Uruguai que seria bicampeão olímpico em 1924 e $1928^{12}$ quebrando assim, a hegemonia do futebol europeu, contribuiu para que o espaço de representação do futebol se tornasse um dos mais importantes na América do Sul (FEDERAÇÃO INTERNACIONAL DE FUTEBOL ASSOCIADO, 2013).

A primeira Copa do Mundo da FIFA foi realizada em 1930, sendo disputada no Uruguai. Apenas quatro seleções fora do continente americano participaram do torneio que acabou sendo vencido pelo então bicampeão olímpico e dono da casa Uruguai. A maioria das seleções europeias desistiu de participar do torneio devido ao descontentamento deste ser disputado em um continente distante. (FEDERAÇÃO INTERNACIONAL DE FUTEBOL ASSOCIADO, 2013).

Em 1938, na terceira Copa do Mundo da FIFA, a seleção austríaca que estava classificada para a fase final do torneio, mas foi impedida de jogar, devido a seu território que já estava anexado a Alemanha Nazista de Hitler, e seus principais jogadores estarem a serviço da seleção alemã que também estava classificada, esse seria uma das primeiras situações geopolíticas que afetariam diretamente a FIFA e o futebol. (FEDERAÇÃO INTERNACIONAL DE FUTEBOL ASSOCIADO, 2013).

Seleções nacionais de outros continentes não tiveram vagas diretas ao campeonato mundial até a década de 1970, e a Inglaterra, criadora do esporte se recusou a disputar o mundial até o ano de $1950^{13}$. (FEDERAÇÃO INTERNACIONAL DE FUTEBOL ASSOCIADO, 2013).

O futebol, com o auxílio da FIFA, acabou por se tornar o esporte mais popular do mundo, dotado de uma grande concentração de renda, patrocínios e um caráter geopolítico, A federação possui atualmente 209 membros reconhecidos, mais do que o comitê olímpico internacional com 193 nações e do que a Organização das Nações Unidas (ONU) (GUERRA, 2012).

Muitas nações recorrem ao reconhecimento por parte da FIFA antes mesmo da ONU, como o caso das nações do leste europeu, após o declínio da URSS. Por congregar um número maior de países que a ONU, esse esporte revela um caráter mundializado, sendo a FIFA a principal organização responsável por essa difusão (JESUS, 1999).

Torneios internacionais entre clubes e seleções foram criados e a partir deles foram gerados renda, tornando a FIFA uma das instituições mais rentáveis do mundo. Patrocínios e cotas de televisão em torneios chancelados pela federação, são responsáveis por mais de noventa por cento da renda arrecadada, atualmente várias empresas de múltiplos ramos do

\footnotetext{
12 Sendo esse ultimo uma final sul-americana contra a Argentina em Amsterdã.

${ }^{13}$ Pois esta nação se considerava hegemônica no esporte, se recusando assim a participar de torneios que colocassem a prova sua hegemonia.
} 
mercado investem milhões de euros e dólares com o objetivo de se tornarem uma das patrocinadoras oficiais dos eventos esportivos promovidos pela organização.

O Programa de Licenciamento de Marca, pelo qual as empresas pagam pelo uso das marcas comerciais da FIFA em suas publicidades, marketing, promoção e venda de seus produtos ou programas licenciados é outra forma de obtenção de renda por meio da instituição. No ciclo de quatro anos entre as copas de 2006 na Alemanha e 2010 na África do Sul, a renda da federação saltou de 2,634 bilhões para 4,189 bilhões (FEDERAÇÃO INTERNACIONAL DE FUTEBOL ASSOCIADO, 2013).

Essa instituição não transformou o esporte em um elemento comum dos mais diversos territórios do planeta, como também um importante fenômeno na dinâmica capitalista atual, se tornando um produto comercializado em todo o mundo.

A FIFA divide sua gestão no esporte pelas suas confederações continentais, que tem a importância de contribuir de forma mais abalizada sobre o conhecimento detalhado de como o futebol está desenvolvendo-se nos diferentes continentes. Essa divisão regional não segue a divisão continental tradicional ${ }^{14}$, nações como a Austrália que geograficamente pertence ao continente da Oceania, estando associada à Confederação Asiática de Futebol (AFC) (FEDERAÇÃO INTERNACIONAL DE FUTEBOL ASSOCIADO, 2013).

A Confederação da América do Norte, Central e Caribe (CONCACAF) aglutina as seleções da América do Norte, da América Central, do Caribe e ainda três nações sul-americanas ${ }^{15}$, sendo uma região somente existente no caráter futebolístico. Israel apesar de pertencer ao continente asiático está filiado a União das Federações Europeias de Futebol (UEFA), principalmente pela iminência de conflitos que poderiam surgir caso Israel enfrentasse adversários históricos do oriente médio (FEDERAÇÃO INTERNACIONAL DE FUTEBOL ASSOCIADO, 2013).

A partir dessa diferente forma de regionalização estabelecida, a FIFA também demonstra seu caráter geopolítico, pois dados culturais, sociais, econômicos e as relações de forças políticas são levadas em conta mais que os continentes que as nações pertencem (FEDERAÇÃO INTERNACIONAL DE FUTEBOL ASSOCIADO, 2013).

A FIFA possui como membros, seis confederações continentais, são elas: a União das Federações Europeias de Futebol (UEFA), a Associação da América do Norte, Central e Caribe (CONCACAF), a Confederação Sul Americana de Futebol (CONMEBOL), e a Confederação Africana de Futebol (CAF), a AFC e a Confederação de Futebol da Oceania (OFC). Essas confederações têm como responsabilidade gerir o futebol de seus continentes, realizando competições de clubes e seleções em suas zonas de atuação. Dada à abrangência da FIFA em caráter mundial, torna-se necessária essa subdivisão da organização (FEDERAÇÃO INTERNACIONAL DE FUTEBOL ASSOCIADO, 2013).

Por sua vez, cada confederação continental possui federações que são as representações das nações pertencentes a cada confederação. Desde 1975, sessenta novas federações foram reconhecidas pela instituição (FEDERAÇÃO INTERNACIONAL DE FUTEBOL ASSOCIADO, 2013). Essas federações estão sujeitas as normas estabelecidas pelos estatutos da FIFA, Sendo essas normas repassadas às federações nacionais por meio de suas confederações continentais.

\footnotetext{
${ }^{14}$ A divisão física.

${ }^{15}$ Guiana, Guiana Francesa e Suriname.
} 
Enquanto privilégios, essas federações tem direito a participação em programas e a igualdade politica em qualquer eleição da instituição (FEDERAÇÃO INTERNACIONAL DE FUTEBOL ASSOCIADO, 2013). Dentre essas federações se destaca a Confederação Brasileira de Futebol $(\mathrm{CBF})$, responsável por gerir o futebol brasileiro. Essa estrutura pode ser visualizada por meio da Figura 1.

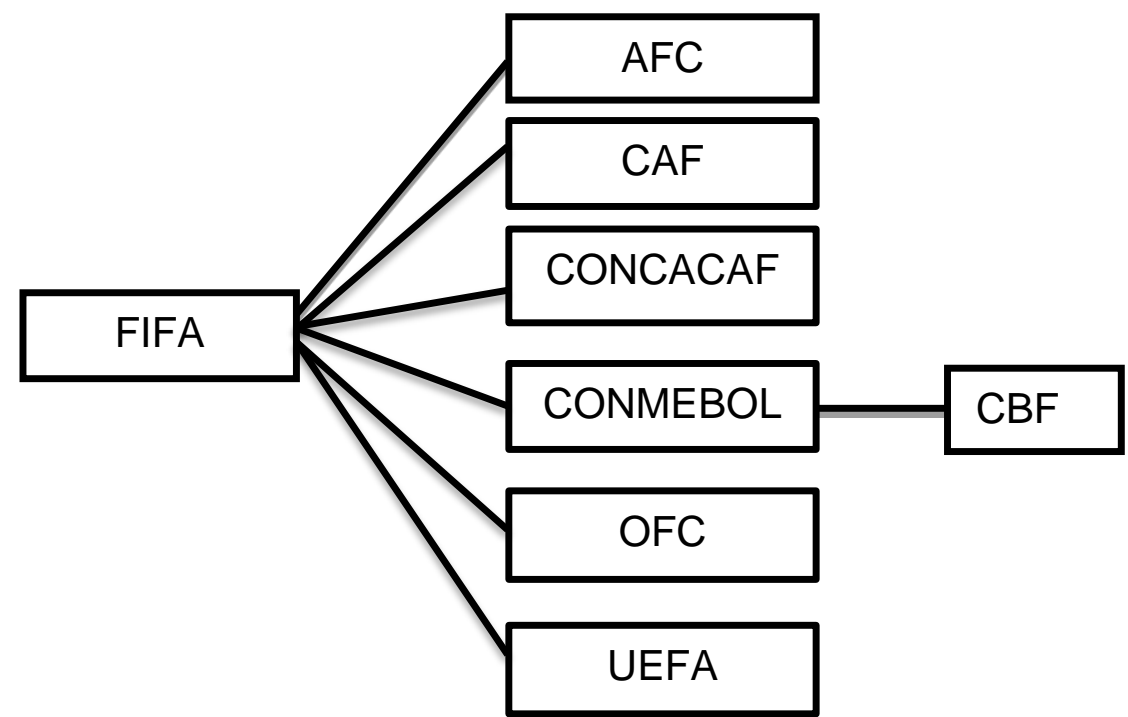

Figura 1 - Gerenciamento do futebol: da escala global a local. Fonte: FIFA (2013).

Não só no âmbito desportivo as federações devem seguir as normas institucionais da FIFA. A Espanha foi excluída da Copa do Mundo de 1938 devido a guerra civil, países como a África do Sul, devido ao regime separatista do Apartheid e a extinta lugoslávia, devido a sangrenta guerra da Bósnia, sofreram sanções da federação, o que os impossibilitou de disputar torneios internacionais, sejam eles a nível continental ou a Copa do Mundo (FEDERAÇÃO INTERNACIONAL DE FUTEBOL ASSOCIADO, 2010).

Em tempos atuais, o futebol se globalizou, é comum vermos o desenvolvimento do desporto em quase todas as cidades do planeta, seja numa prática amadora ou profissional. Os times de futebol se tornaram grandes transnacionais, que importam e exportam jogadores. Novas culturas se misturam e ao mesmo tempo, pensamentos nacionalistas são reforçados, como no caso dos negros que jogam futebol nos Cárpatos, ou das antigas batalhas travadas entre o protestantismo (Rangers) e o catolicismo na Escócia (Celtic), onde a globalização une povos distintos através de clubes de futebol, e ao mesmo tempo cria rivalidades étnicas improváveis em outros períodos da história (FOER, 2005). O futebol transcendeu as barreiras esportivas e atingiu as mais diversas estruturas socioeconômicas e culturais transformando-se, portanto num mecanismo de reprodução social.

\section{O FUTEBOL NO CENÁRIO NACIONAL BRASILEIRO}

Trazido por funcionários e operários ingleses, o futebol em território brasileiro seguiu sobre dois caminhos, um por meio dos trabalhadores das linhas férreas que criaram os primeiros clubes de várzea, e o outro através dos estudantes de classe média alta paulistana que aprendiam o desporto em clubes ingleses (SEVCENKO, 1994). 
Com a chegada do descendente de ingleses, Charles Miller ao Brasil, após alguns anos estudando em Southampton, na Banister Court School, trazendo em sua bagagem camisa, calção, chuteira e duas bolas, além de um manual de regras do esporte, foi realizada a primeira partida de futebol oficial do Brasil (MAXIMO, 1999).

Em São Paulo, foi realizada a primeira partida oficial de futebol no Brasil. No pequeno campinho de várzea do Carmo, onde residia à alta classe média paulistana, Miller teve como companheiros na partida, jovens descendentes de famílias européias que haviam assim como ele, ido estudar em escolas dos mais diferenciados países europeus (MAXIMO, 1999). Miller os ensinou as regras do jogo e lhes conferiu atribuições como juiz e bandeirinhas.

O primeiro jogo foi realizado com as regras oficialmente estabelecidas na Inglaterra em 1863, ocorreu em abril de 1895, entre as equipes do São Paulo Railway ${ }^{16}$ e The São Paulo Gaz (JESUS, 2002), após a primeira partida, outros jogos foram realizados em terrenos mais nobres da sociedade paulistana (MAXIMO, 1999).

A partir da chegada de Miller, o futebol se popularizou rapidamente em São Paulo, onde associações desportivas já inseriam o futebol em seus currículos e divulgavam o novo esporte para a sociedade paulistana, uma dessas agremiações era a Liga Atlética da Academia do Largo do São Francisco, criada em 1919, que seria a primeira associação atlética universitária do Brasil (SEVCENKO, 1994), o Brasil ainda era um país pouco urbanizado, sendo São Paulo o principal centro de localização da indústria, como o futebol é um esporte de origens urbanas, é facilmente explicável o motivo que o levou a se estabelecer primeiramente em São Paulo.

A partir da primeira partida de futebol, outras agremiações passaram a inserir o futebol como prática desportiva, e os primeiros clubes especificamente voltados para o futebol começaram a surgir, não somente em São Paulo, como de início, mas também no Rio de Janeiro, Belo Horizonte, Porto Alegre, Recife e Salvador. Dessas seis cidades, quatro já possuíam uma população maior que cem mil habitantes no país no inicio do século XX; o Rio de Janeiro com 691 mil habitantes, São Paulo com 239 mil habitantes, Salvador com 205 mil habitantes e Recife com 116 mil habitantes (SANTOS, 1998).

No entanto, deve-se salientar que o futebol surgiu no Brasil em um período em que nossas cidades principais não possuíam uma articulação entre si, sendo a inserção do esporte nas cidades feita de forma desconectada, através de diversas incursões independentes, tendo as maiores cidades e mais modernas os ingredientes necessários para a efetivação dessa inovação (JESUS, 1998).

A inserção do futebol no Brasil aconteceu de forma simultânea e desconectada, a despeito do vasto território do país, mesmo utilizando o modelo adotado em outras localidades internacionais, no Brasil, foram reforçadas rivalidades locais e o regionalismo. (JESUS, 2002).

O primeiro clube formado essencialmente por brasileiros foi o Mackenzie College, fundado em 1898 (JESUS, 2002). A respeito dos demais clubes de futebol no Brasil,

foram surgindo os primeiros times de verdade. Em 1896, o São Paulo Athletic Club, seria o primeiro a aderir ao novo esporte, logo seguido do Sport Club Germania (1889), de Mackenzie Athletic Association (1898), Sport Club Internacional (1898), Clube Atlético Paulistano (1900), já com nome

${ }^{16}$ Time pelo qual Charles jogou. 
aportuguesado. Em Campinas, fundou-se a Associação Atlética Ponte Preta (1900). No Rio de Janeiro o Fluminense Foot-ball Club (1902), o Rio Foot-ball Club (1902), o Botafogo Foot-ball Club, o America Foot-ball Club, o Bangu Athletic Club (os três últimos em 1904). Flamengo e Vasco da Gama já existiam desde o fim do século, ambos dedicando-se ao remo. Em Porto Alegre, foi fundado o Esporte Clube Rio Grande (1900); em Minas, o Sport Club Belo Horizonte (1904); em Recife, o Club Náutico Capeberibe (1901); em Salvador, o Vitória Foot-ball Club (1905). Vale ressaltar que o futebol brasileiro nasceu como brinquedo de menino rico. (MAXIMO, 1999, p. 182).

No Rio de Janeiro, o futebol foi rapidamente inserido na sociedade. A até então capital federal era o maior parque industrial do país no inicio do século XX, possuía também uma grande classe abastada existente. Em 1902 foi criado o Fluminense Football Club, o primeiro clube brasileiro voltado apenas para a prática do futebol e que fora fundado por famílias da elite do Rio de Janeiro. Já em 1904, o sucesso da criação do Fluminense, incentivou a criação de outros clubes. Em 1906, foi realizado o primeiro campeonato carioca de futebol, torneio que perdura com edições anuais desde então (JESUS, 1998).

Em São Paulo, a difusão do esporte se deu de forma mais rápida e acentuada do que em qualquer outra cidade do Brasil, a cidade vivia um momento de explosão do crescimento urbano. A implantação de ferrovias para a expansão do café, por meio de trabalhadores ingleses, que acabaram por se estabelecer na cidade criando escolas na região e propiciando a chegada da modernidade a cidade. São Paulo se torna propício a receber inovações (JESUS, 2002).

A criação em 1902, do primeiro torneio entre clubes do Brasil, o Campeonato Paulista de Futebol, mostrou a forte influência dos imigrantes ingleses. São Paulo Athletic, Sport Club Germânia $^{17}$, Mackenzie Athletic Association, Sport Club Internacional, e o Club Athletic Paulistano foram os participantes do torneio (LIMA, 2002).

Em Salvador, o futebol se inseriu em clubes onde existia a prática do Cricket ${ }^{18}$. Em 1904, aconteceu o segundo torneio de futebol local em todo o Brasil, o campeonato baiano, grande parte graças principalmente a grande quantidade de empreendimentos comerciais ingleses existentes na cidade, sendo o primeiro campeão baiano, a equipe do Internacional formada completamente por jogadores ingleses (JESUS, 1999). O futebol na cidade não possui uma ligação com outras cidades brasileiras, mas sim com o global através do comércio.

O futebol chegou ao Rio Grande o Sul através dos ingleses que levaram o futebol via construção de estradas de ferro de Buenos Aires e Montevidéu para as cidades gaúchas (JESUS, 2001). Em Porto Alegre a forte influência dos descendentes alemães facilitou a inserção do futebol na cidade.

Dado aos valores cultivados por uma sociedade europeia que entendia a importância de práticas desportiva enquanto maneira de manutenção da saúde e da qualidade de vida, clubes como o Grêmio Football Porto-Alegrense e o Fussball foram criados com o apoio de instituições financeiras importantes na cidade de Porto Alegre, como por exemplo, o Banco Alemão, que financiou a criação do Grêmio (JESUS, 2005).

\footnotetext{
${ }^{17}$ Atual E.C. Pinheiros

${ }^{18}$ Jogo similar ao baseball, original do Reino Unido e que se popularizou principalmente em ex-colônias inglesas como a Índia e Paquistão.
} 
Porto Alegre crescia rapidamente nos primeiros anos do século $X X$, já possuindo uma população superior a cem mil habitantes. Em 1900, quando surge o Sport Club Rio Grande ${ }^{19}$, o porto da cidade de Rio Grande movimentara o dobro de seu congênere em Porto Alegre. A capital gaúcha só irá ultrapassar seu rival no em comércio exterior no ano de 1908, aproximadamente nessa época em que a capital desponta como pólo maior do futebol gaúcho. Existem, portanto, várias correlações entre a evolução do fenômeno futebol e as transformações no território (JESUS, 1998).

Esse crescimento urbano facilitou possibilitou a inserção de clubes populares com o Sport Club Internacional em 1909 (JESUS, 2005). Na capital, os Campeonatos metropolitanos já eram organizados a partir de 1910.

Em Recife, a conexão da cidade com o exterior também foi o principal fator de inserção do futebol, a relação com os ingleses não está somente direcionada aos estudantes que trouxeram o esporte para a cidade, como também os primeiros jogos serem disputados entre o Sendo o Sport Club do Recife, o primeiro clube fundado na cidade, e clubes formados apenas por funcionários de companhias inglesas sediadas no Recife (GASPAR, 2010), porém, devido à cidade não ser mais um grande centro graças a pouca dinamicidade de suas atividades urbanas, a evolução e desenvolvimento do futebol se deu de forma mais lenta que nos grandes centros do país (JESUS, 1998).

Ao mesmo tempo em que houve o aparecimento de clubes criados por membros da elite brasileira, o futebol de várzea ordenado por operários das fábricas que se expandiam principalmente em São Paulo e no Rio de Janeiro também construía seu território, clubes como o Sport Club Corinthians Paulista, o Palestra Itália ${ }^{20}$, o Bangu Athletic Club, além de muitos outros clubes de bairro passaram a existir nas várzeas das grandes cidades, principalmente em São Paulo (LIMA, 2002).

O futebol de várzea se popularizou na mesma intensidade e no mesmo período do futebol das elites, surgindo campos de futebol alocados nos bairros operários, os campeonatos de futebol na várzea se tornaram cada vez mais frequentes, no entanto ainda havia uma resistência das classes aristocráticas ao futebol praticado de forma desordenada, fazendo-se distinção entre o futebol disputado pelas elites e o futebol jogado pela várzea, como se esses tratassem de esportes diferentes (JESUS, 2002).

Clubes da várzea tinham dificuldades para entrar na liga oficial da cidade, sendo somente a partir da década de 1920 tornou-se impossível evitar que as equipes de várzea jogassem com as profissionais, o futebol passou a ser um elemento chave do cotidiano da classe operária paulistana (JESUS, 2002), encontramos assim uma relação de um esporte com o território. Podemos afirmar que, a partir

Da Várzea do Carmo, os campos se alastraram por toda a cidade, sobre tudo nos bairros operários, situados ao longo das estradas de ferro [...] A cidade vivia intensamente a experiência do trabalho fabril e passava a conhecer a necessidade imperativa de sociabilidade e lazer; sobretudo aos domingos. Os clubes de várzea mantinham equipes de futebol e promoviam atividades sociais

\footnotetext{
${ }^{19}$ Clube mais antigo do futebol brasileiro ainda em funcionamento.

${ }^{20}$ Atual Sociedade Esportiva Palmeiras.
} 
[...] Além destes, tornavam-se comuns os clubes formados a partir de empresas, fábricas ou grupos profissionais. (ANTUNES, 1998, p. 92).

Embora seja difícil saber quando o futebol se tornou a "paixão nacional", indícios de tal acontecimento levam a final do campeonato Sul-Americano em 1919, onde o Brasil venceu o Uruguai no novo e moderno estádio das laranjeiras ${ }^{21}$ pelo placar de um a zero depois de três prorrogações. Arthur Friedenreich, autor do gol que deu a vitória ao Brasil, sendo carregado nos ombros pelos torcedores cariocas, sendo esta a conquista do primeiro titulo internacional da Seleção Brasileira de Futebol, o esporte passou a tomar dimensões cada vez maiores e a paixão pelo mesmo só fez crescer (MÁXIMO, 1999).

Com o futebol inserido na sociedade brasileira, este entra em uma nova fase a partir de 1933, em que os clubes começam a se tornar profissionais. Diferentemente dos casos da Argentina ou Uruguai, o futebol braseiro entrou na era do profissionalismo com o intuito de encerrar a hegemonia de clubes que venciam campeonatos com elencos que possuíam jogadores mestiços ou negros (MÁXIMO, 1999).

Como os times possuíam em seus elencos sócios do clube, que poderiam frequentar as áreas sociais do mesmo, tornou-se necessário profissionalizar o futebol e contratar os jogadores negros como funcionários sem a necessidade de matricularem esses jogadores no quadro social do clube, não atoa, os clubes mais elitistas foram os líderes do movimento profissionalista (MÁXIMO, 1999).

A profissionalização permitiu a grandes jogadores brasileiros ganharem a merecida fama ao defenderem clubes de grande popularidade, o que tornou possível ao futebol brasileiro conquistar os títulos mais importantes de sua história. Dentre eles os campeonatos mundiais, o que também foi possível aos uruguaios graças à incorporação de jogadores negros (MÁXIMO, 1999).

Mesmo que em 1950, após o fatídico gol de Ghighia que causou a derrota de virada da seleção brasileira para os uruguaios no último jogo da fase final da Copa do Mundo do Brasil, todos apontassem um negro como o principal culpado pela derrota brasileira, o goleiro Barbosa, o futebol continuou em seu rumo de inserção da etnia negra na prática desportiva e na sociedade (MÁXIMO, 1999).

Os títulos da Seleção Brasileira de Futebol contribuíram para o crescimento do esporte no país, os títulos mundiais conquistados através de apresentações magníficas dentro de campo como a conquista do tricampeonato mundial em 1970 sobre a Itália, ou a campanha não vitoriosa de $1982^{22}$ quando o conceito de futebol arte fora perfeitamente denotado a uma equipe, acabaram por dá notabilidade global ao futebol brasileiro. (MÁXIMO, 1999).

Atualmente o futebol se tornou um negócio milionário e global, e o futebol brasileiro com uma grande quantidade de jogadores de alta técnica se inseriu nesse mercado, lançando jogadores para diferentes países do mundo, alguns deles possuindo valores de mercado que superam a casa da dezena de milhões de reais, o que situa o esporte como um dos elementos de identidade nacional. Cada vez mais o futebol está associado não somente a uma prática

\footnotetext{
${ }^{21}$ Pertencente ao clube mais rico do Rio de Janeiro, o Fluminense.

${ }^{22}$ Em derrota para a mesma Itália.
} 
desportiva quer seja ela profissional ou amadora ${ }^{23}$, mas, também, a um nível global e local de relações sociais e espaciais. (LIMA, 2002).

\section{O FUTEBOL EM SUA DIMENSÃO LOCAL: A CIDADE DE NATAL}

O fenômeno futebol começou a ser praticado no estado do Rio Grande do Norte em sua capital, assim como em outros estados brasileiros por meio de jovens estudantes, que foram a Europa em finais do século XIX e início do século XX e trouxeram conhecimento e as regras desse desporto (SOBRINHO; CÉSAR, 2008).

No caso do Rio Grande do Norte, o futebol foi inserido por meio dos irmãos Fabrício e Fernando Pedroza, que chegaram a Natal em 1903, trazendo uma bola e o conhecimento não tão apurado da regra, sendo os irmãos Pedroza, com um grupo de amigos da elite natalense os fundadores da primeira equipe de futebol do estado, o Sport Club Natalense em 1904 (SOBRINHO; CÉSAR, 2008).

A prática do esporte até a década de 1910 se dava em terrenos descampados, sendo as regras do futebol ainda não conhecidas em sua totalidade, cabendo a Alberto Roselli, conhecedor das regras do esporte, organizar o esporte na cidade (SOBRINHO; CÉSAR, 2008).

A partir de 1910, os primeiros clubes da cidade começaram a surgir: o Natal Foot-Ball (1910), o Potiguar Foot-Ball (1910), e o English Team (1910), todos esses clubes formados por membros das famílias mais abastadas da cidade ${ }^{24}$, sendo a Praça Pedro Velho, o local onde eram realizados os primeiros jogos de futebol entre essas equipes (SOUZA, 2001).

Em meados da década de 1910, outros clubes continuaram a aparecer, destacando-se, dentre eles o Atheneu Foot-Ball Club, o Atlântico Foot-Ball Club, o Partido Republicano Paulista Foot-Ball Club, o Partido Republicano Conservador Foot-Ball Club, o Humaytá Foot-Ball Club e o Atlético Sport Club, todos acabaram tendo uma curta existência (SOUZA, 2001).

Ainda no ano de 1915, surgem as duas equipes que viriam a se tornar os maiores rivais do futebol da cidade. Em 29 de junho do referido ano, surge o ABC Futebol Clube, e em 14 de julho do mesmo ano, é fundado o América Futebol Clube.

Já em 1917, é a vez do terceiro mais importante clube da cidade, o Alecrim Futebol Clube $^{25}$. Sendo essas três equipes as únicas ainda existentes do futebol das primeiras décadas do século XX na cidade. Em 1929, com a inauguração do Stadium Juvenal Lamartine, o futebol natalense encontrou o seu primeiro território adequado para essa prática desportiva (SOUZA, 2001). Sobre a criação do estádio Juvenal Lamartine "O estádio esportivo seria a consagração da vida esportiva do estado. Esse prédio monumental que se erguia na cidade seria mais um símbolo do avanço da cidade a civilidade." (MARINHO, 2008, p. 119).

\footnotetext{
${ }^{23}$ Vale ressaltar os olheiros, que vão a campos de várzea identificar bons jogadores que poderiam colocar em equipes profissionais.

${ }_{24}^{24}$ O que novamente denota o caráter elitista do esporte em seus primórdios.

${ }^{25}$ Há discordâncias quanto à data em que realmente o clube tenha sido fundado, havendo informações do próprio clube sobre a fundação da equipe em 15 de agosto de 1915, com o intuito de ajudar as crianças pobres do bairro do até então bairro da zona rural de Natal.No entanto, leva-se em consideração a data de fundação oficial, reconhecida pela Federação Norte-Rio-Grandense de futebol.
} 
Em 1967, começou a ser construído o principal local para prática do futebol até então ${ }^{26}$, o Estádio Humberto Alencar Castelo Branco ${ }^{27}$, foi inaugurado em 1972, sendo o seu nome modificado para João Cláudio de Vasconcelos Machado ${ }^{28}$ a partir de 1989 (SOBRINHO; CÉSAR, 2008).

Em 14 de Junho de 1918 surge o organismo responsável por gerir o futebol do estado, a Liga de Esportes Terrestres do Rio Grande do Norte, que teria seu nome modificado em 1976 para Federação Norte-Rio-Grandense de Futebol (FNF), o objetivo da Liga era gerir o futebol e o atletismo do estado, possuia entre seus membros fundadores o $A B C$, o América e o Centro Esportivo Natalense (FEDERAÇÃO NORTE-RIO-GRANDENSE DE FUTEBOL, 2013). Poucos meses após sua criação, a Liga já tinha organizado um campo de futebol no bairro do Tirol, e um campeonato interclubes (MARINHO, 2008).

A liga de esportes terrestres tinha no sentido de "organizar competições, delegar normas, intermediar intrigas e medidas para educar o público" (MARINHO, 2008, p.114). Esse prezar pela ordem fazia com que o presidente da Liga, o doutor Potygar Fernandes, solicita-se o aumento do número de carros que iriam para o Tirol em dias de jogos do campeonato (MARINHO, 2008). Sobre a influência dos esportes no urbano prossegue

A vida esportiva na cidade exercia indiretamente uma pressão sobre as organizações do transporte público, fundamentalmente para a união dos bairros, e expansão da malhar urbana, mas que, segundo as reclamações registradas nos jornais, muitas vezes era deficiente (MARINHO, 2008, p. 115).

No ano seguinte a criação da FNF, foi realizado o primeiro campeonato estadual de futebol tendo como primeiro campeão do estado o América Futebol Clube. Equipe que conseguira sua oficialização jurídica um anos antes, e que era formado basicamente por jogadores oriundos do bairro da Cidade Alta, o primeiro Bairro da cidade. O clube contava com poucos recursos e era formado por estudantes, comerciantes, funcionários privados e funcionários públicos (AMÉRICA FUTEBOL CLUBE, 2013).

Já aquele que viria a ser sua antítese na cidade, $O A B C$ Futebol Clube, era formado por jovens natalense, alguns praticantes de remo e pertencentes a famílias abastadas da Ribeira ( $A B C$ FUTEBOL CLUBE, 2013), segundo bairro de Natal, conhecido no período como cidade baixa, em oposição ao primeiro bairro da cidade (SOUZA, 2001).

A partir da década de 1920, o futebol estava deixando suas origens nas classes mais abastadas de lado, e os clubes começavam a se profissionalizar, graça a mercantilização do esporte. A grande quantidade de torcedores nas partidas atraiu os comerciantes, e serviu como forma de obtenção de renda para os clubes fazendo com que estes não mais só dependessem da contribuição financeira de seus sócios (MARINHO, 2008). Podemos afirmar, portanto, que a rivalidade entre essas equipes surgiu de uma rivalidade bairrista pré-existente na Natal do início do século XX.

\footnotetext{
${ }^{26}$ Estádio derrubado em meados de 2012, para que no mesmo espaço fosse construído um novo estádio denominado Arena das Dunas, que servirá como um dos palcos para os jogos da Copa do Mundo da FIFA 2014.

${ }^{27}$ Nome do estádio em homenagem ao presidente militar após o golpe de 1964.

${ }^{28}$ Conhecido popularmente como Machadão. 
Os comerciantes também viam na venda de ingressos uma forma de obtenção de renda para suas lojas, ao comercializarem os ingressos (MARINHO, 2008). Com a obtenção de uma maior renda, em 1929, o América pode comprar o terreno no bairro do Tirol, onde hoje está a sua sede-oficial. A principio este servia também como centro de treinamento, apesar de ser considerado um local muito distante (AMERICA FUTEBOL CLUBE, 2013).

$O A B C$ inaugurou em janeiro de 2006, no Complexo Sócio-Esportivo Vicente Farache ${ }^{29}$, numa área de 10,2 hectares, o seu estádio particular, o Maria Lamas Farache, mas conhecido pela a alcunha de Frasqueirão, se tornando o primeiro clube da cidade a ter um estádio próprio, tornando o clube hegemônico no controle de um território voltado para a prática do futebol ( $A B C$ FUTEBOL CLUBE, 2013).

Atualmente, $A B C$ e América não dependem exclusivamente do dinheiro dos ingressos para manutenção de suas instituições, eles também recorrem a soluções de seus problemas financeiros com programas de sócios torcedores - voltando à essência primordial de arrecadação desses clubes em suas origens -, dinheiro de cotas de televisão e a utilização de patrocínios associados à marca do clube, além da venda de materiais com a marca do clube, como por exemplo, camisas, bolsas e bonés.

O futebol reflete em Natal-RN, o mesmo caráter globalizado que em outras cidades brasileiras, sendo a prática do esporte, cada vez mais associada ao poder mercantil, no entanto, o futebol amador ainda resiste nos campos de bairros ou nas práticas de um futebol "sem regras" nas calçadas, nos terrenos baldios, nas praias ou em campos e minicampos amadores.

\section{REFERÊNCIAS BIBLIOGRÁFICAS}

1. ABC FUTEBOL CLUBE. História, frasqueirão: um sonho concreto. [S.I.]: ABC Futebol Clube, 2013. Disponível em: <http://www.abcfc.com.br/frasqueirao-historia/>. Acesso em: 17 jan. 2013.

2. História. [S.I.]: ABC Futebol Clube, 2013. Disponível em: <http://www.abcfc.com.br/historia/>. Acesso em: 17 jan. 2013.

3. AMÉRICA FUTEBOL CLUBE. História. [S.I.]: América Futebol Clube, 2013. Disponível em: <http://www.americadenatal.com.br/o-america/historia/o-clube/>. Acesso em: 17 jan. 2013.

4. ANTUNES, Fátima Martin. Futebol de fábrica em São Paulo. 1998. 190 f. Dissertação (Mestrado em Sociologia) - Faculdade de Filosofia, Letras e Ciências Humanas, Universidade de São Paulo, São Paulo, 1998.

5. BLATTER, Joseph Sepp. Arquivos da diretoria internacional de futebol associado. [S.I.]: Prefácio do presidente da FIFA. 1998. Disponível na Internet: <http://ssbra.org/html/laws/ifab.html > .Acesso em: 16 jan. 2013.

6. BRUNI, Jose Carlos. Apresentação. Revista USP. São Paulo, n. 22, jun./jul./agos. p.7, 1994.

7. DAMATTA, Roberto et al. Futebol. In: . Lance imperdível!: um retrato do esporte no Brasil. 1. ed. Rio de Janeiro: Lance!, 2010. cap. 2, p. $39-45$.

\footnotetext{
${ }^{29}$ Ex-jogador e diretor técnico do clube, que se notabilizou pelo seu amor e assistência financeira ao clube entre as décadas de
} 1930 e 1940 (ABC FUTEBOL CLUBE, 2013). 
8. FEDERAÇÃO INGLESA DE FUTEBOL. The F.A.Cup. [S.I.]: Federação Inglesa de Futebol, 2013. Disponivel

em: <http://www.thefa.com/Competitions/FACompetitions/TheFACup/History/historyofthefacup >. Acesso em: 05 fev. 2013.

9. FEDERAÇÃO INTERNACIONAL DE FUTEBOL ASSOCIADO. A evolução das regras do jogo. [S.I.]: Federação Internacional de Futebol Associado, 2012. Disponível em: <http://pt.fifa.com/worldfootball/news/newsid=1569726.html> . Acesso em: 31 jan. 2013.

10. Folha de dados. [S.I.]: Federação Internacional de Futebol Associado, 2010. Disponível em: <http://www.fifa.com/mm/document/fifafacts/mencompwc/51/97/75/fs201_19a_fwc-prel-history.pdf>. Acesso em: 15 de jun. 2013.

11. . Copa do mundo FIFA da África do Sul 2010. [S.I.]: Federação Internacional de Futebol Associado, $2011 . \quad$ Disponível em: <http://pt.fifa.com/worldcup/archive/southafrica2010/organisation/media/newsid=1473439 /index.html >. Acesso em: 11 de jan. 2013.

12. _. Early years 1924 - 1930. [S.I.]: Federação Internacional de Futebol Associado, 2013. Disponível em: <http://www.fifa.com/mm/document/fifafacts/mcwc/ip-201_02e_fwcorigin_8816.pdf> Acesso em: 10 de fev. 2013.

13. _. Documentos da FIFA. [S.I.]: Federação Internacional de Futebol Associado, 2013. Disponível em: <http://pt.fifa.com/aboutfifa/officialdocuments/doclists/aboutfifa.html >. Acesso em: 11 de jan. 2013.

14. _. Finanças. [S.I.]: Federação Internacional de Futebol Associado, 2013. Disponível em: <http://pt.fifa.com/aboutfifa/finances/income.html>. Acesso em: 16 jan. 2013.

15. __ Organização. [S.I.]: Federação Internacional de Futebol Associado, 2013. Disponível em: <http://pt.fifa.com/aboutfifa/organisation/associations.html> . Acesso em: 16 jan. 2013.

16. FIGUEIREDO, Danilo José. Tlachtli: esporte ou ritual de sangue?. Klepsidra: Revista virtual de historia, São Paulo, n. 13, abr. 2002. Disponível em: <http://www.klepsidra.net/klepsidra13/teotlachtli.htm>. Acesso em: 29 fev. 2013.

17. FOER, Franklin. Como o futebol explica o mundo: um olhar inesperado sobre a globalização. Tradução de Carlos Alberto Medeiros. Rio de Janeiro: Zahar, 2005. 216 p.

18. FUTEBOL INGLÊS ONLINE. Escócia 0 Inglaterra 0. [S.I.]: Futebol Inglês Online, 2012. Disponível em: <http://www.englandfootballonline.com/Seas1872-00/187273/M0001Sco1872.html>. Acesso em: 07 fev.2013.

19. GORGAZZI. Osvaldo José; BOBROWSKY, Josef. Algumas informações sobre a história precoce de futebol na Argentina. The Record Sport Soccer Statistics Foundation, Buenos Aires, fev. 1999. Disponível em: <http://www.rsssf.com/tablesa/arg-early-info.html> . Acesso em: 28 jan. 2013.

20. GUERRA, Ricardo. O que ninguém sabre a FIFA. Estadão, São Paulo, 16 jul. 2012. Disponível em: < http://blogs.estadao.com.br/ricardo-guerra/o-que-ninguem-sabe-sobre-afifa/?doing_wp_cron=1360687407.6123969554901123046875> . Acesso em: 25 jan. 2013.

21. JESUS, Gilmar Mascarenhas de. Futebol e modernidade no Brasil: a geografia histórica de uma inovação. Revista digital Efdeportes.com. Buenos Aires, ano 3. n. 10. Maio 1998. 
22. - Geopolítica do futebol. Revista eletrônica Scripta Nova de geografia e ciências sociais, Barcelona, n. 170, set. 1999.

23. . Considerações teórico-metodológicas sobre a difusão do futebol. Revista eletrônica Scripta Nova de geografia e ciências sociais, Barcelona, n. 69, ago. 2000.

24. A bola nas redes e o enredo do lugar: uma geografia do futebol e de seu advento no Rio Grande do Sul. 2001. 268 f. Tese (Doutorado em Geografia) - Programa de Pós-Graduação em Geografia Humana, Universidade de São Paulo, São Paulo, 2001.

25. Várzeas, operários e futebol: uma outra geografia. Geographia - Revista do Programa de Pós-Graduação em Geografia da Universidade Federal Fluminense, Niterói, v. 4, n. 8, p. 84-92, 2002.

26. . A mutante dimensão espacial do futebol: forma simbólica e identidade. Revista Espaço e Cultura da Universidade Estadual do Rio de Janeiro: Rio de Janeiro, n. 19-20, p. 61 70, jan/dez. 2005.

27. LIMA, Marcos Antunes de. As origens do futebol na Inglaterra e no Brasil. São Paulo: Klepsidra, 2002. Disponível em: <http://www.klepsidra.net/klepsidra14/futebol.html> acesso em: 22 jan. 2013.

28. MARINHO, Márcia Maria Fonseca. Natal também civiliza-se: sociabilidade, lazer e esporte na Belle Époque natalense (1900 -1930). 2008. 139.f. Dissertação (Mestrado em História) Faculdade de História, Universidade Federal do Rio Grande do Norte, Natal, 2008.

29. MÁXIMO, João. Memórias do futebol brasileiro. Revista Estudos Avançados da Universidade de São Paulo, São Paulo, v. 13, n. 37, p. 179-188, set./dez. 1999.

30. SANTOS, Joel Rufino dos. História política do futebol brasileiro. 1. ed. São Paulo: Brasiliense, 1981.

31. SANTOS, Milton. A urbanização brasileira. 4. ed. São Paulo: Hucitec, 1998.

32. SEVCENKO, Nicolau. Futebol, metrópoles e desatinos. Revista USP (Dossiê Futebol), São Paulo, n. 22, jun/jul/ago. 1994.

33. SOBRINHO, José Correia; CÉSAR, Iran Hermenegildo. Torcidas organizadas de futebol: metamorfoses de um fenômeno de massa. Revista Eletrônica Inter-Legere. n. 3, p. 01-04, jul./dez. 2008.

34. SOUZA, Itamar. Nova História de Natal: o futebol. Diário de Natal, Natal, 15 maio. 2001. p. 96 $-98$.

35. SUA PESQUISA .COM. História do futebol: origens do futebol, chegada do futebol no Brasil, Charles Miller, FIFA, Copa do Mundo. [S.I.]: Sua pesquisa.com, 2013. Disponível em: <http://www.suapesquisa.com/futebol/> Acesso em: 12 Jan 2013.

36. TRAVINHA ESPORTES. Origem e história da FIFA. [S.I.]: Travinha Esportes, [2010]. Disponível em: <http://www.travinha.com.br/eventos-desportivos/149-copa-do-mundo-de-futebol/180fifa-a-historia> Acesso em: 14 fev 2013. 